\title{
Science
}

\section{Recent aeolian erosion and deposition in the north polar plateau of Mars}

\author{
J.A.P. Rodriguez ${ }^{1,2}$, Kenneth L. Tanaka ${ }^{3}$, Yves Langevin ${ }^{4}$, Mary Bourke ${ }^{2,5}$, Jeffrey \\ Kargel $^{6}$, Phil Christensen ${ }^{7}$, and Sho Sasaki ${ }^{1}$
}

${ }^{1}$ National Astronomical Observatory, Mizusawa, Japan; ${ }^{2}$ Planetary Science Institute, Tucson, Arizona, USA, alexis@psi.edu ; ${ }^{3}$ Astrogeology Team, U.S. Geological Survey, Flagstaff, Arizona, USA; ${ }^{4}$ Institut d'Astrophysique Spatiale, CNRS / Univ. Paris Sud, France; ${ }^{5}$ Oxford University Center for the Environment, University of Oxford, Oxford OX1 3QY; ${ }^{6}$ Department of Hydrology and Water Resources, Univ. of Arizona, AZ 85721, USA;

${ }^{7}$ Department of Geological Science, Arizona State University, Arizona, USA.

Citation: Mars 3, 29-41, 2007; doi: 10.1555/mars.2007.0003

History: Submitted: December 8, 2006; Reviewed: March 13, 2007; Resubmitted: August 24, 2007; Accepted: October 3, 2007; Published: December 3, 2007

Editor: Oded Aharonson, Division of Geological and Planetary Sciences, California Institute of Technology

Reviewers: Oded Aharonson, Division of Geological and Planetary Sciences, California Institute of Technology; Sarah Milkovich, Jet Propulsion Laboratory

Open Access: Copyright (c) 2007 Rodriguez et al. This is an open-access paper distributed under the terms of a Creative Commons Attribution License, which permits unrestricted use, distribution, and reproduction in any medium, provided the original work is properly cited.

\begin{abstract}
Background: Planum Boreum, the north polar plateau of Mars, displays four extensive low-albedo regions covered with widespread sedimentary deposits that are thick enough to partly or completely suppress the signature of the residual water ice that forms the uppermost zone of the polar layered deposits. These sedimentary deposits appear to have a source primarily in a buried sedimentary layer preferentially exposed along the walls and floors of some polar troughs. The deposits extend and drape over circum-polar dunes.

Method: The data analyses in this research were conducted with Geographic Information Systems (GIS) mapping tools. The following data sets have been used: (1) Mars Odyssey (MO) Thermal Emission I maging System (THEMIS) summer north polar visible light mosaics at $18 \mathrm{~m} /$ pixel and $32 \mathrm{~m} /$ pixel, as well as $18 \mathrm{~m} /$ pixel visible multiband images (THEMIS mosaic provided by P.H. Christensen and the THEMIS Team, Arizona State U.), (2) Mars Express (MEX) High Resolution Stereo Camera (HRSC) images at $10 \mathrm{~m} /$ pixel, (3) Mars Global Surveyor (MGS) Mars Orbiter Camera (MOC) narrow-angle (NA; $>1.4 \mathrm{~m} /$ pixel) and a wide-angle image mosaic, 64 pixels/degree, (4) Mars Reconnaissance Orbiter (MRO) High Resolution Imaging Science Experiment (HiRISE) camera images at resolutions that range from $31.8 \mathrm{~cm} /$ pixel (with $1 \times 1$ binning) to $63.5 \mathrm{~cm} /$ pixel (with $2 \times 2$ binning), (5) MGS Mars Orbiter Laser Altimeter (MOLA) 512 pixels/degree digital elevation models, and (6) MEX OMEGA Vis/IR imaging spectrometer. False color maps have been derived from OMEGA data in which all three color planes are proportional to albedo (0.1: level 0, 0.45: level 255). The red plane scales inversely with the fraction of the area covered by ice, derived from the band strength at $1.5 \mu \mathrm{m}$ (factor of 0 for $30 \%$ fractional ice coverage within the pixel, factor of 1 for ice-free pixels). The $\mathrm{H}_{2} \mathrm{O}$ ice spectral signatures have been observed by OMEGA in November 2004, during early northern summer (Ls $109^{\circ}$ to $114^{\circ}$ ). The incidence at the time of observations was nearly optimal for such latitude regions $\left(57.6^{\circ}\right)$. Sampling on the ground was 1.7 to $2 \mathrm{~km}$.

Conclusion: The most recent history of the north polar plateau of Mars includes highly dynamic sedimentary processes involving large-scale wind-driven mass transfer from Planum Boreum towards its periphery. The proposed polar processes involved: (I) retreat along undulations within upper layered deposits (ULD), thereby exposing underlying dark sedimentary deposits, (II) mobilization of these deposits to form extensive dark mantles, which are water-ice free and that terminate in circum-polar terrains, and (III) complete removal of these deposits leading to the exhumation of pre-existing troughs.
\end{abstract}




\section{Introduction}

The polar regions of both Earth and Mars have volatile-rich deposits, the histories of accumulation of which are thought to have been predominantly controlled by their respective climatic histories. Geologic studies of the north polar plateau of Mars reveal the following stratigraphic sequences and relationships.

The youngest stratigraphic unit is the residual water-ice cap, generally $\leq 3 \mathrm{~m}$ thick, displays pits, cracks, and knobs at horizontal scales of tens of meters in Mars Global Surveyor's (MGS) Mars Orbiter Camera (MOC) images (Thomas et al. 2000). The underlying layers are darker and make up a tens-of-meter-thick sequence of relatively high-albedo upper layered deposits (ULD), which appear to lack unconformities. The ULD consist of at least three or four and as many as seven layers detectable in MOC images (e.g., MOC images E20-00005 and S22-01165), and their deposition may be linked to a climatic stage of low obliquity during the past 4 to 5 million years (Laskar et al., 2002) during which volatile accumulation in the northern polar region was the dominant process forming north polar-layered deposits. The ULD rest unconformably on lower, darker layered deposits (LLD) (Tanaka 2005, Thomas et al. 2000; Howard et al. 1982).

The LLD appear to consist of indurated, competent materials having local unconformities that indicate a complex history of erosion and deposition (Tanaka 2005, Malin and Edgett 2001). The LLD are made up of $>250$ layers at MOC resolution that are generally 1-10 m thick and best exposed in poleward-facing scarp walls. The layers form distinct sequences characterized by albedo (Tanaka 2005, Milkovich and Head 2005, Laskar et al. 2002). The total thickness of the LLD may exceed $1000 \mathrm{~m}$, but the local thickness is likely to be variable due to the apparent rugged topography of the underlying materials that form a sizable fraction of Planum Boreum and the LLD’s eroded topography (Tanaka 2005).

The underlying deposits form cross-bedded and evenly, relatively thick (tens of meters) bedded materials that collectively reach hundreds to more than a kilometer in thickness and may date back to the Early Amazonian (Tanaka 2005, Fishbaugh and Head 2005, Herkenhoff 2003, Byrne and Murray 2002, Malin and Edgett 2001), These materials are exposed in steep scarps and form much of the floor of Chasma Boreale; the cross-bedded materials appear to be largely made up of sand as dark dunes originate from where they are exposed.

Despite the fact Planum Boreum on Mars is among the most geologically active surfaces on the planet, and its stratigraphic record displays considerable evidence for deposition of ice and atmospheric dust driven by the water and carbon dioxide cycles of Mars (e.g. Thomas et al. 1992), the nature of the erosional process that produced the unconformities and other erosional features in the north polar-layered deposits remains poorly understood. Among the more enigmatic erosional features are the polar troughs, for which early models of formation included insolation (e.g., Howard 1978), Cutts 1973) and glacial deformation (e.g., Weijermars 1986). Wind is also a major erosional process of the polar layered deposits that likely is important in forming the polar troughs and Chasma Boreale, along with fields of yardangs (Kolb and Tanaka 2001, Howard 2000). Chasma Boreale has also been attributed to fluvial erosion from subglacial outbursts of meltwater (Fishbaugh and Head 2002, Benito et al. 1997). Although many studies have interpreted glacial movement and ice relaxation for the materials of Planum Boreum (e.g., Pathare and Paige 2005, Fisher 2000, Fishbaugh and Head, 2000), other studies suggest that little such deformation has occurred.

We have identified extensive water-ice free low albedo surfaces in Planum Boreum, which correspond to zones that are extensively mantled by dark sedimentary deposits. In this investigation we have carried out a general morphologic and morphometric characterization of these low albedo surfaces in order to understand the nature of the sedimentary processes that led to the emplacement of these geologic materials, and their significance in the overall history of accumulation and erosion of polar layered deposits.

\section{Geomorphology of low albedo surfaces in Planum Boreum}

Our examination of north polar visual summer mosaics, obtained by the Mars Odyssey's Thermal Emission Imaging System (THEMIS) in combination with a surface water-ice map produced by spectral data obtained by the Mars Express' (MEX) OMEGA (Visible and Infrared Mineralogical Mapping Spectrometer) instrument, reveals the existence of (1) a surface of Planum Boreum that has a continuous high albedo and which consists almost entirely of water ice, (2) surfaces of Planum Boreum that show an almost continuous low albedo and which are mostly free of water ice, and (3) a mixed albedo surface characterized by having an overall diffuse water-ice signature (Figure 1). The low and mixed albedo surfaces of Planum Boreum have a combined area of $\sim 200,000,000 \mathrm{~km}^{2}$, or about 16 per cent of the total surface area of the northern polar plateau.

In the zones of Planum Boreum that have an almost continuous low albedo (Figure 1), both the polar troughs and the plateau surfaces along their peripheries, are largely free of water-ice (e.g. Figures 2a and 2c). On the other hand, in mixed albedo zones of Planum Boreum, the water-ice signature is predominantly suppressed along polar troughs and ranges from diffuse to strong in the adjacent plateau surfaces (Figure $2 \mathrm{~b}$ and $2 \mathrm{~d}$ ). In addition, in the high albedo zone of Planum Boreum, where the surface consists of primarily water ice there are numerous troughs the surfaces of which are water-ice free (blue arrow in Figure 1b).

THEMIS VIS spring and summer (relatively frost-free) images show that in these terrains the low albedo water-ice free surfaces correspond to terrains where dark materials form extensive mantles, which commonly consist of superposed deposits with serrated margins (e.g., Figures 3 and 4), which in this paper we refer to as "north polar veneers". At MOC and HiRISE resolutions, the margins of north polar veneers appear diffuse and to consist of multiple streaks, which drape over (but do not bury) the underlying ULD surface textures 
such as bedding planes and knobby surfaces (Figure 4).The OMEGA spectra ratios from a region with a weak ice signature and from an ice-free region with a similar albedo (Figure 2a) indicate that areas with no significant ice signatures require at least several millimeters of mantling by water-free geologic materials, so as to prevent any large ice grain from sticking out. On the other hand, within polar troughs these mantles appear to be thick enough as to completely mute the surface texture of the underlying LLD (e.g., Figures 3a and 3c).

The plateau surfaces that display a mixed surface albedo and have a reduced water-ice signature correspond to locations where north polar veneers have a relatively high surface albedo (typically light gray tones) (Figure $3 \mathrm{~b}$ and 3d).

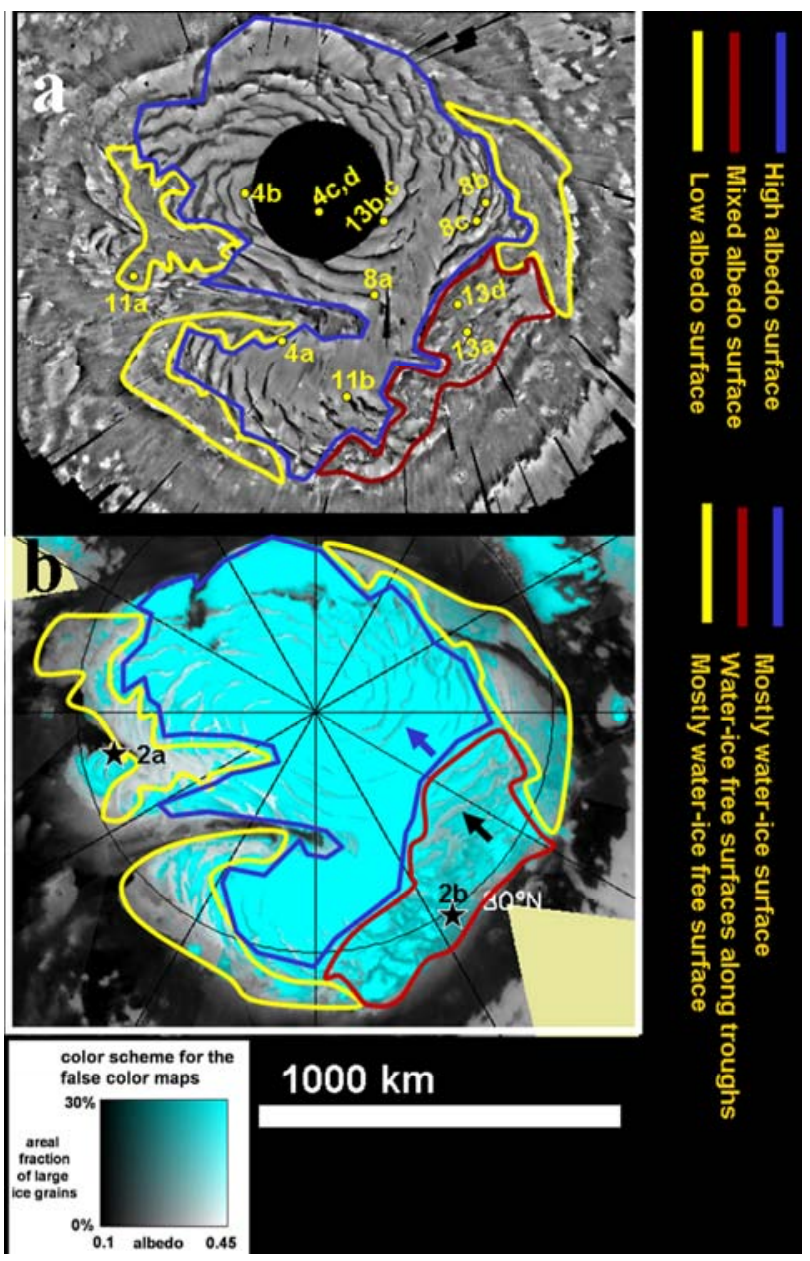

Figure 1. Views of the north polar region of Mars. (a) THEMIS visual-range mosaic of summertime images ( 32 $\mathrm{m} / \mathrm{pixel}$ ). Outlined are surface zones of high, mixed and low albedos. Locations of Figures 4, 8 and 13 are shown. (b) False-color map of surface water-ice (cyan areas) detected by OMEGA spectra. Outlined are surface zones that display high (cyan areas), mixed (dark tones of cyan), and low (gray to dark zones) water-ice signatures. Locations of Figures $2 \mathrm{a}$ and $2 \mathrm{~b}$ are shown. (figure1.jpg)

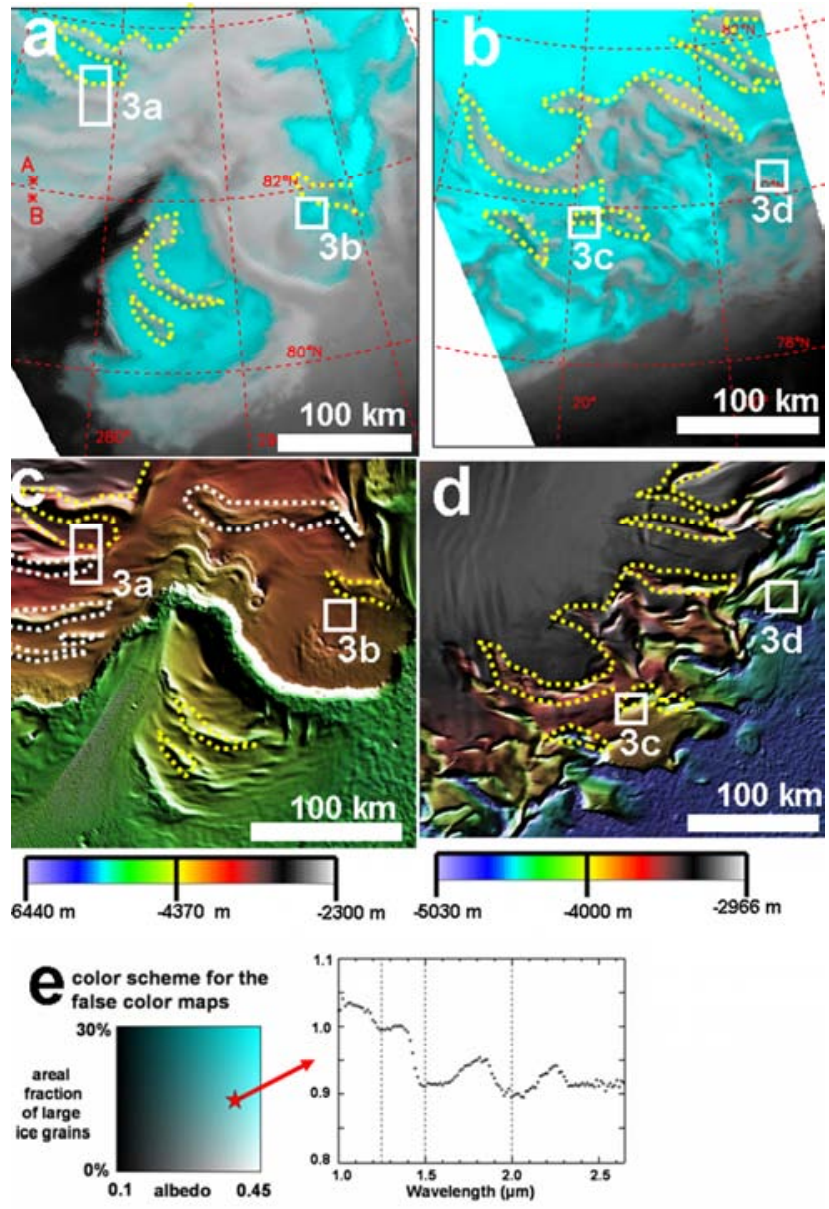

Figure 2. (a, centered at $\left.284.74^{\circ} \mathrm{W}, 82.33^{\circ} \mathrm{N}\right)$ and (b, centered at $21.56^{\circ} \mathrm{W}, 81.09^{\circ} \mathrm{N}$ ) are false color OMEGA maps of water-ice spectral signatures, and respectively correspond to zones where there are low and diffuse water-ice signatures (see Figure $1 \mathrm{~b}$ for their contexts and locations). Both (c) and (d) are 512 pixels/degree MOLA DEMs that respectively show the topographic contexts of panels $a$ and $b$. Yellow dots in panels $a$ and $b$ show boundaries of water-ice free surfaces, which correspond to the margins of polar troughs (yellow dots in panels $c$ and d). The white dots in panel c show the margins of polar troughs in zones where both the troughs and the adjacent plateaus form water-ice free surfaces. (e) Left: Color scheme for panels $a$ and $b$. Right: Graph of the ratio of two OMEGA spectra from a region with a weak ice signature (red letter $A$ in panel a) and from an ice-free region with a similar albedo (red letter $B$ in panel A). The resultant spectrum corresponds to a sub-pixel spatial mixing of polar deposit terrain (spectrally nearly featureless) with large grained ice ( $600 \mu \mathrm{m}$ to $1 \mathrm{~mm}$ ) as demonstrated by the relatively strong $1.25 \mu \mathrm{m}$ band and the saturated 1.5 and 2 $\mu \mathrm{m}$ bands. This spectrum has been adequately modeled by areal mixing of the spectrum of residual ice and that of an ice-free component ( $15 \%$ and $85 \%$ respectively in this case), and it provides the link between band strengths and areal coverage by large ice grains, which is used to define the color scale for the maps. The locations of Figures 3a-d are indicated. (figure2.jpg) 


\section{Morphology of initiation zones of north polar veneers}

Polar troughs that contain dark interior deposits (e.g., Figures $3 c, 5,6$, and 7) typically comprise the locations where north polar veneers initiate. These dark interior deposits commonly form mantles that partly, or continuously, cover the floors of polar troughs (Figure 7). Nevertheless, in some polar troughs they form a single dark layer located at the contact between the LLD and the ULD which locally passes into pits and grooves (Figure 8).

Geology of Gemina Lingula. A plateau (Gemina Lingula) southeast of Chasma Boreale includes two
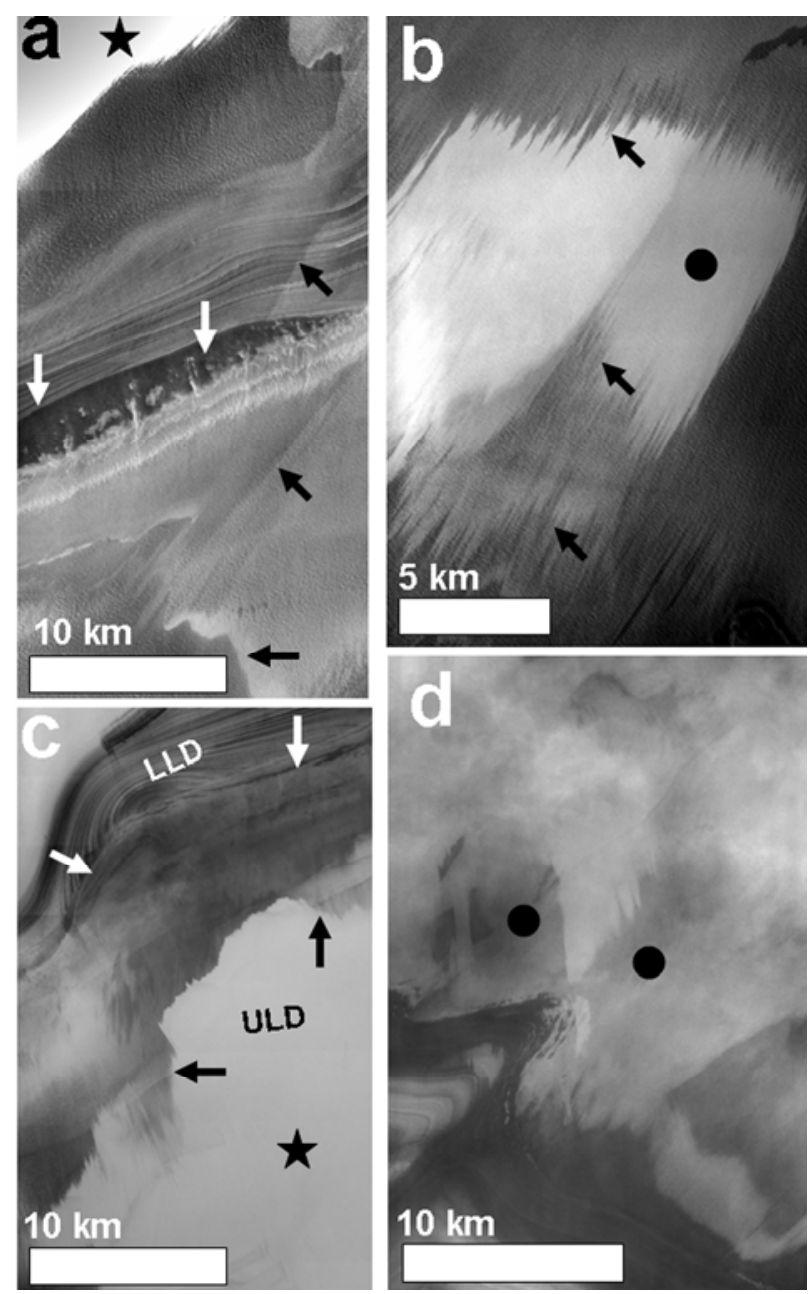

Figure 3. THEMIS VIS spring and summer (relatively frost-free) images of low albedo water-ice free surfaces in Planum Boreum. In these regions high albedo surfaces (star symbols) consist of water-ice, mixed albedo surfaces (black dots) show diffuse water-ice signatures, and dark mantles (black arrows) and ridges (white arrows) correspond to surfaces where the water-ice signature is absent. (See Figure 2 for topographic contexts and water-ice maps; panel a centered at $281.13^{\circ} \mathrm{W}, 83.94^{\circ} \mathrm{N}$, panel b centered at $295.96^{\circ} \mathrm{W}, 81.74^{\circ} \mathrm{N}$, panel c centered at $20.79^{\circ} \mathrm{W}$, $79.67^{\circ} \mathrm{N}$, and panel $\mathrm{d}$ centered at $35.67^{\circ} \mathrm{W}, 79.94^{\circ} \mathrm{N}$, which are parts of THEMIS VIS V13035006, V13446006, V13393002 and V13717002, respectively.) (figure3.jpg) geomorphologically distinct zones.

(1) The first is a high albedo zone that forms the only extensive part of Planum Boreum, which is not cut by polar troughs. Instead, this zone, where the surface of the ULD consists of water-ice, is marked by widespread undulations, which have a typical vertical relief of a few tens of meters (Figure 5). Numerous ULD undulations extend from, or align parallel/sub-parallel to, polar troughs, which typically contain water-ice free dark interior deposits and have a typical vertical relief of $100 \mathrm{~m}$ (Figure 6). In some cases, where the ULD undulations pass into polar troughs, their surfaces appear locally degraded into grooves--the floors of which

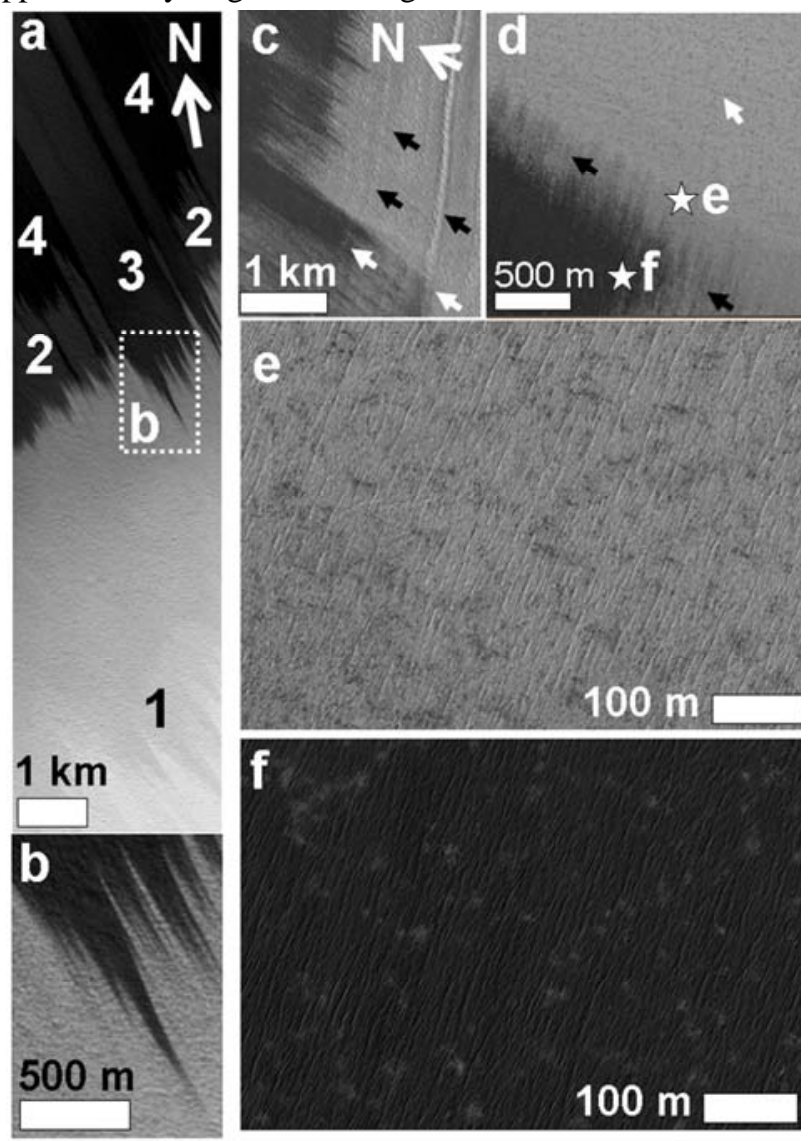

Figure 4. High-resolution views of veneers on Planum Boreum, Mars. (a) Sequence of superposed veneers (younger and darkening in the sequence from 1 to 4 ). A close-up view of veneer 3 (b) shows a diffuse margin made up of numerous streaks. Notice how the ULD surface has a knobby texture, which is apparent but muted where there are north polar veneers (Part of MOC R2301243, centered at $22.06^{\circ} \mathrm{W}, 83.68^{\circ} \mathrm{N}$ ). (c) Margin of a north polar veneer that obscures (white arrows) layers that in this region form the ULD surface (Part of MOC R2300271, centered at $87.65^{\circ} \mathrm{W}, 86.93^{\circ} \mathrm{N}$ ). (d) North polar veneer that has a diffuse margin (black arrows). Notice how the adjacent surface of the ULD shows randomly distributed patches of dark materials. (e) An up-close view of part of a ULD surface reveals dense systems of surface grooves. (f) The veneers-forming materials mantle (but do not bury) the groove systems. (Panels $d-f$ are parts of HiRISE TRA_000882_2705, centered at $5.24^{\circ} \mathrm{E}, 89.42^{\circ} \mathrm{N}$ ). (figure4.jpg) 
have a relatively lower albedo than the surrounding ULD surfaces (Figure 6 and THEMIS V12924005). The difference

in elevation between the trough floor that contains the dark interior deposits and the adjacent trough where these are absent is $\sim 100 \mathrm{~m}$. Assuming that there are no abrupt changes in the elevation between the surface of the LLD materials underlying the dark interior deposits and the adjacent exposed LLD trough floors, this value represents the local thickness of the dark interior deposits in this polar trough (Figure 6).

(2) A low albedo zone that is largely free of water-ice, and which is along the periphery of the high albedo zone. This terrain is extensively dissected by polar troughs, most of which contain dark interior deposits that form the source regions of veneers that extensively mantle the plateau

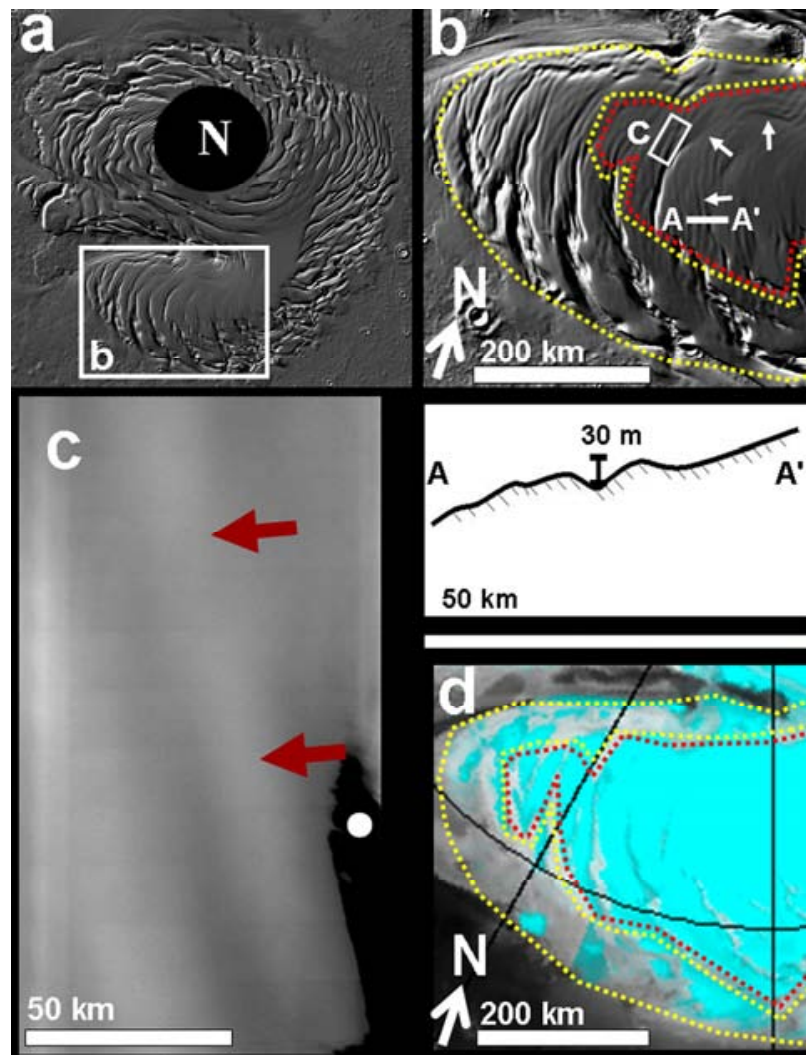

Figure 5. (a) MOLA derived shaded-relief view of the north polar plateau of Mars, Planum Boreum. The white box shows the location of Gemina Lingula. (b) Shaded-relief view from MOLA DEM of Gemina Lingula. Shown are ULD undulations that extend from polar troughs and are oriented subparallel to the troughs (white arrows) (image centered at centered at $\left.340.58^{\circ} \mathrm{W}, 82.31^{\circ} \mathrm{N}\right)$. A MOLA-extracted elevation profile $\left(A-A^{\prime}\right)$ shows an ULD undulation that has a vertical relief of $30 \mathrm{~m}$. (c) Part of THEMIS VIS V13407001 showing a ULD undulation (red arrows), which is parallel to a trough that contains dark interior deposits (centered at $344.29^{\circ} \mathrm{W}, 82.70^{\circ} \mathrm{N}$ ). (d) OMEGA-derived false color map of the surface water-ice distribution in Gemina Lingula. The yellow dots outline a zone of Planum Boreum that is mostly free of water-ice, and the red dots outline an adjacent zone where the surface consists mostly of water-ice (ice-content color scale as in Figure 1). (figure5.jpg) surfaces in the region (Figure 5).

A close examination of a polar trough in this region reveals (a) a section where the floor is completely covered with dark interior deposits, and (b) an adjacent section where the dark interior deposits form a ramp along a trough's flank and the underlying LLD form outcrops along the base of the trough (Figure 7). The plateau surfaces that form the margins of the trough section where the floor consists of dark interior deposits are more extensively covered by north polar veneers than the section where the floor partly consists of LLD.

In summary, dark interior deposits within polar troughs are the source regions of the north polar veneers that form the low albedo water-ice free surfaces in Planum Boreum (Figure 1).

\section{Morphology of accumulation zones of north polar veneers}

The accumulation of north polar veneers on Planum Boreum does not appear to be influenced by the variations in the local topography (e.g., Figures 7a and 8a). The lengths and widths of individual north polar veneers range from a few hundreds of meters (e.g., Figure 4) to a few tens of kilometers (e.g., Figure 7), and they commonly terminate in sedimentary deposits that are situated around the periphery of Planum Boreum (Figure 9). These sedimentary deposits are thick enough in places so as to embay and bury dunes that form part of the circum-polar erg (Figure 10).

\section{Morphologic characteristics of the upper layered deposits in zones of north polar veneer occurrence}

The surface of Planum Boreum in zones of veneer occurrence displays various types of surface erosional morphologies. For example, Figure 11a shows a THEMIS VIS view of an edge of Planum Boreum that consists of a knobby ridge oriented perpendicular to the trends of numerous polar veneers that cover part of the polar plateau. In MOC and HiRISE images, the surface of the ULD and the residual ice cap in zones of veneer occurrence commonly display striations (grooves and ridges) (Figures $4 \mathrm{e}, 11 \mathrm{~b}$, and 11c). A close-up view of a scarp that forms the margin of a striated surface reveals the existence of alternating low and high albedo layers. The scarp passes down into a series of benches that are covered in dark mantles, presumably the result of preferential retreat along the dark layers (Figures 11c and d).

\section{Characteristics of the sedimentary environment for the north polar veneers}

Stratigraphy. We have identified low albedo deposits that are stratigraphically between the LLD and ULD. We refer to the unit as the "intermediate deposits" (ID, Figures 12 and 14). The ID appear to have a highly variable thickness as indicated by the facts that they form a thin layer along trough walls and relatively thick deposits on trough floors $(\sim 100 \mathrm{~m})$. The thickness variations suggest that the emplacement of the ID took place over a densely troughed terrain, where troughs 
acted as sedimentary traps. This proposition is consistent with the formation of the polar troughs having taken place during and/or after the accumulation of the LLD, perhaps due to extensive surface erosion associated with the emplacement of the ID (Rodriguez and Tanaka 2007).

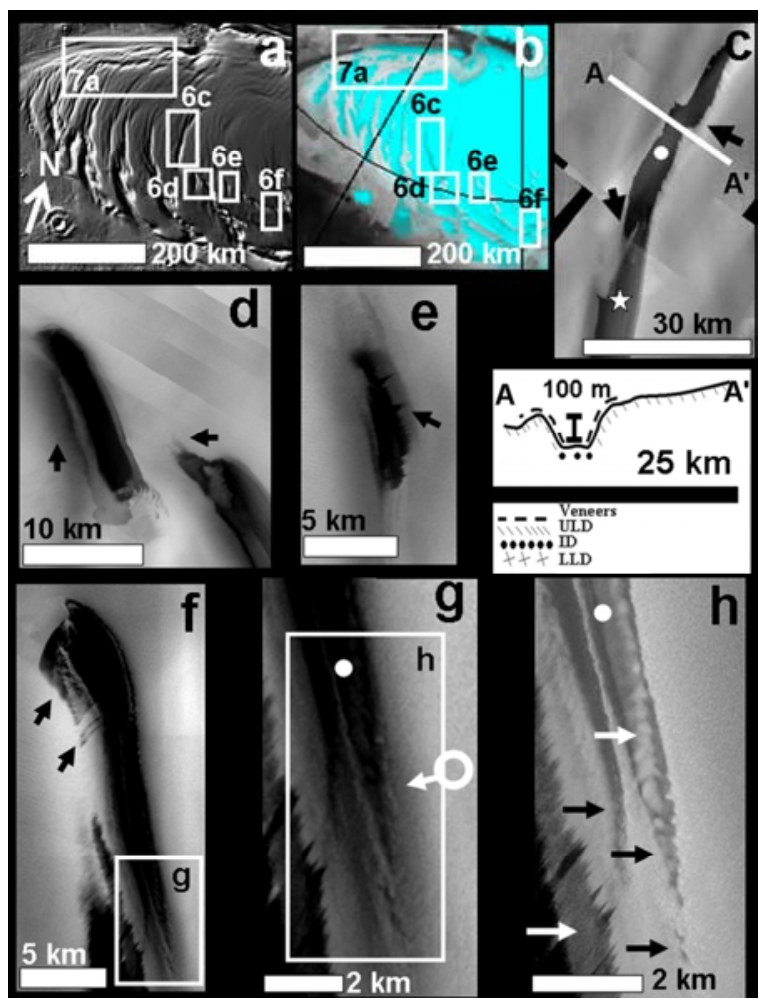

Figure 6. (a-b). Shaded-relief view from MOLA DEM of Gemina Lingula and related OMEGA derived false color map of the surface water-ice distribution (images centered at centered at $\left.340.58^{\circ} \mathrm{W}, 82.31^{\circ} \mathrm{N}\right)$. Shown are the locations of various polar troughs (c-e), the floors of which are free of water-ice, including the location of Figure $7 \mathrm{a}$ (panel c centered at $344.33^{\circ} \mathrm{W}, 81.93^{\circ} \mathrm{N}$, panel d centered at $348.76^{\circ} \mathrm{W}, 81.00^{\circ} \mathrm{N}$, and panel e centered at $353.42^{\circ} \mathrm{W}$, $\left.80.88^{\circ} \mathrm{N}\right)$. These enclosed troughs contain dark deposits that form the source regions of north polar veneers (black arrows). An elevation profile across part of a polar trough that contains dark interior deposits shows a maximum vertical relief of $100 \mathrm{~m}$. The difference in elevation between the surface of these dark interior deposits (white dot, $-3730 \mathrm{~m}$ ) and the adjacent polar trough surface free of dark materials (white star, $-3630 \mathrm{~m}$ ) is one hundred meters, which may represent the thickness of these deposits (parts of THEMIS VIS 32 pixels/degree mosaic). (f) Enclosed polar trough infilled with dark interior deposits that form the source regions of north polar veneers (black arrows). The trough extends south into a ULD undulation (view centered at $1.38^{\circ} \mathrm{W}, 80.31^{\circ} \mathrm{N}$ ). A close-up view (g) of the zone where the trough passes into the surface undulation shows surface grooves marked by irregular scarps (the arrowed circle shows the direction of illumination) (part of THEMIS VIS 13274005). Notice how the surface of the grooves appears to have a lower albedo than the surrounding ULD and appears differentially eroded (h). (Panels $\mathrm{f}$-h are parts of THEMIS VIS 13506006). (figure6.jpg)

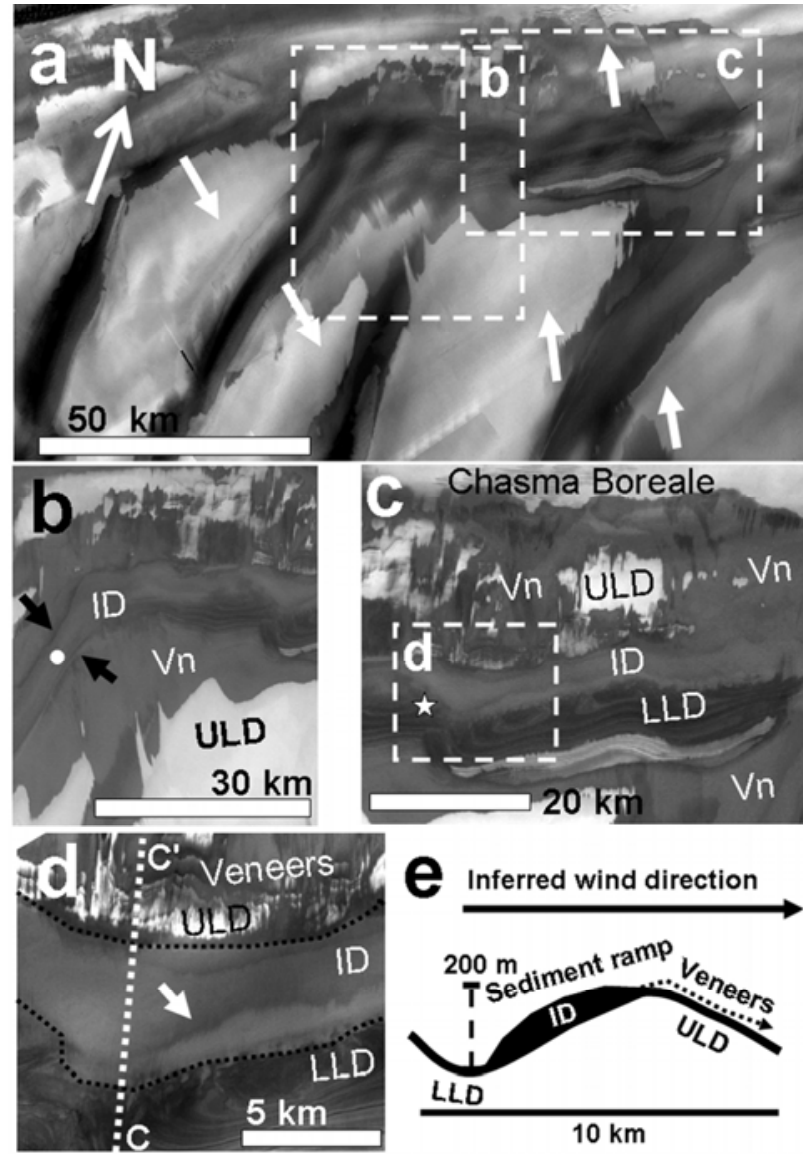

Figure 7. (a) Low albedo zone in western Gemina Lingula centered at $326.19^{\circ} \mathrm{W}, 83.04^{\circ} \mathrm{N}$, where the plateau surfaces are extensively mantled by north polar veneers that spread away from dark interior deposits within polar troughs. The white arrows indicate the inferred direction of sedimentary surface migration, which is also assumed to represent the wind direction (part of a THEMIS VIS summertime mosaic ( $18 \mathrm{~m} /$ pixel) superimposed on a MOLA-derived shaded relief image, see Figure 6 a for context and location). (b) Section of a polar trough infilled with low albedo materials (black arrows indicate trough margins), which form the source region of very extensive veneers. ID = intermediate deposits and $\mathrm{Vn}=$ north polar veneers. (HRSC image centered at $\left.323.71^{\circ} \mathrm{W}, 82.78^{\circ} \mathrm{N}\right)$. This section passes into a zone of the same polar trough $(\mathbf{c})$, where dark interior deposits overlie the LLD (HRSC image centered at $\left.329.27^{\circ} \mathrm{W}, 83.21^{\circ} \mathrm{N}\right)$. The difference in elevation between the surfaces of the dark interior deposits (white dot in panel b) where they cover the trough floor (white star), and the surface of the LLD outcrops is $\sim 100 \mathrm{~m}$. (d) Close-up view of area in panel c centered at $325.83^{\circ} \mathrm{W}, 82.99^{\circ} \mathrm{N}$ (part of THEMIS VIS V13208001). Black dots outline the low albedo interior deposits within this section of the polar trough, and the white arrow shows the serrated margins of veneers. These deposits form a sedimentary ramp up the margin of the trough from where north polar veneers extend (e). (figure7.jpg) 


\section{Discussion}

The fact that in some places the contact between the ID and the underlying LLD forms an angular unconformity (e.g., Figure 8c) adds further support for the existence of a major erosional hiatus that preceded the emplacement of the ID. The ID appear to be absent below the ULD in some trough walls, especially those that face south, which may indicate that the ID form discontinuous deposits. Possible ID discontinuities may represent zones of no net deposition, which may have occurred where there were locally energetic surface winds during ID accumulation. Alternatively, the contact between the ULD and the ID may not be exposed in zones where the

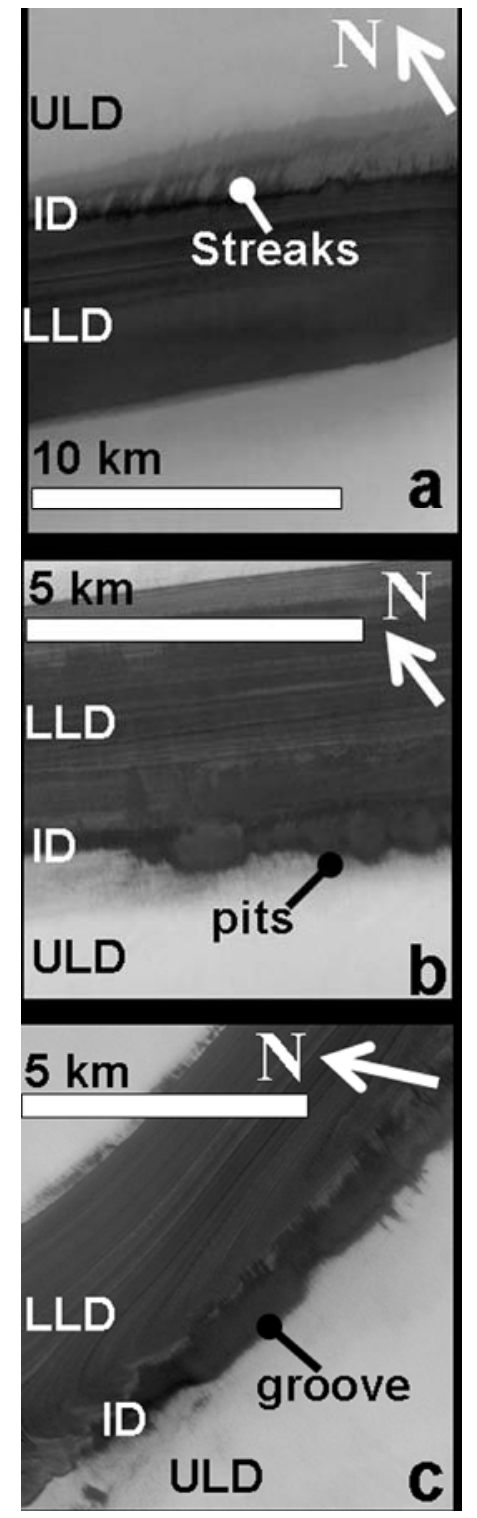

Figure 8. Exposures of an ID layer at the boundary between the LLD and the ULD. In some cases, the ID appear (a) to form the source region of dark streaks (part of THEMIS V12857003 centered at $24.43^{\circ} \mathrm{W}, 85.26^{\circ} \mathrm{N}$ ), (b) to be eroded into pits (part of THEMIS V13154005 centered at $84.53^{\circ} \mathrm{W}, 82.92^{\circ} \mathrm{N}$ ), or (c) to be eroded into a groove (part of THEMIS V13304001 $78.61^{\circ} \mathrm{W}, 83.25^{\circ} \mathrm{N}$ ). See Figure $1 \mathrm{a}$ for contexts and locations. (figure8.jpg) residual ice overlaps the LLD.

The fact that (1) north polar veneers (Vn in Figures 12 and 14) commonly extend from dark interior deposits within polar troughs, (2) these two surficial deposits are free of water-ice, (3) there is a correlation between the degree of mantling by surface veneers and the size of the dark interior deposits within polar troughs (e.g., Figures 7b and 7c), and (4) some polar trough surfaces are free of water-ice but have adjacent plateau surfaces that contain modest amounts of water-ice, which is consistent with incipient veneer mantling of the residual ice (Figures $1 \mathrm{~b}$ and $2 \mathrm{~b}$ ), suggest that ID materials comprise the veneers' primary source regions. This proposition is further supported by the fact that ID layers locally include pits and grooves that form the source regions of north polar veneers (Figure 8), which indicates that the ID are more highly erodible than the underlying LLD and overlying ULD. North polar veneers have tapering ends similar to those of windstreaks, (e.g., Zimbelman and Williams 1996; Howard 2000), which suggests they are aeolian deposits. In fact, high winds across much of Planum Boreum are indicated in mesoscale atmospheric circulation models (Tyler and Barnes 2005).

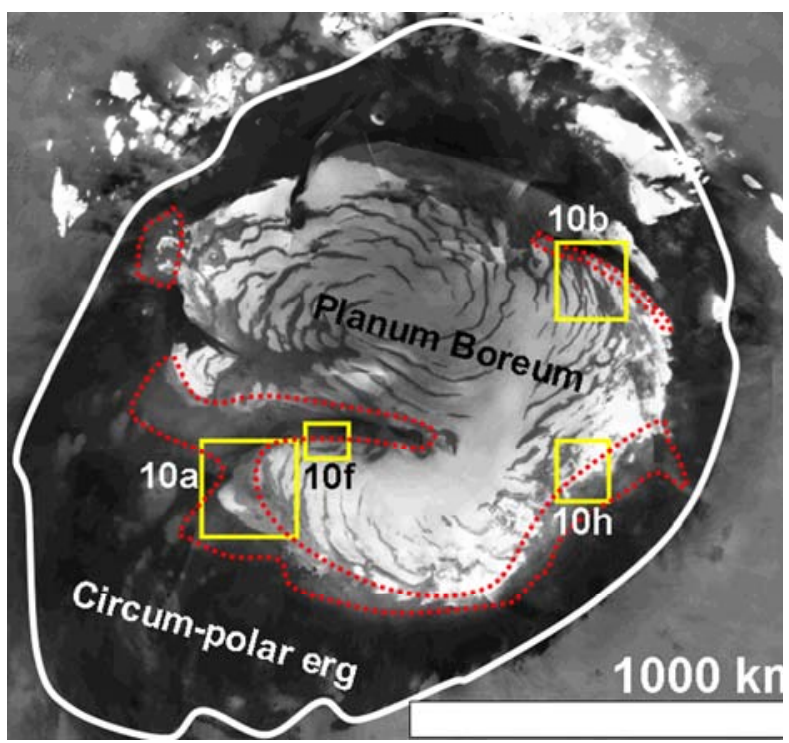

Figure 9. View of Planum Boreum, Mars. The white line marks the outer margin of the north polar circum-polar erg and the red dots outline sedimentary deposits where numerous north polar veneers terminate (MOC wide-angle image mosaic, 64 pixels/degree; Malin Space Science Systems). The locations of the panels in Figure 10 are shown. (figure9.jpg)

Assuming that the tapering ends of the north polar veneers are indicative of the formative wind directions, then ID dispersion appears to commonly occur perpendicular to the central axis of polar troughs (e.g., Figures 6 and 7), which can explain the extensive north polar veneer mantling of plateau surfaces forming the margins of polar troughs that contain ID materials (e.g., Figures 1 and 7). Although our observations generally are not consistent with the north polar veneers being frost streaks (e.g., Thomas and Veverka 1978) (Figure 7), we do not rule out that some frost streaks may be 


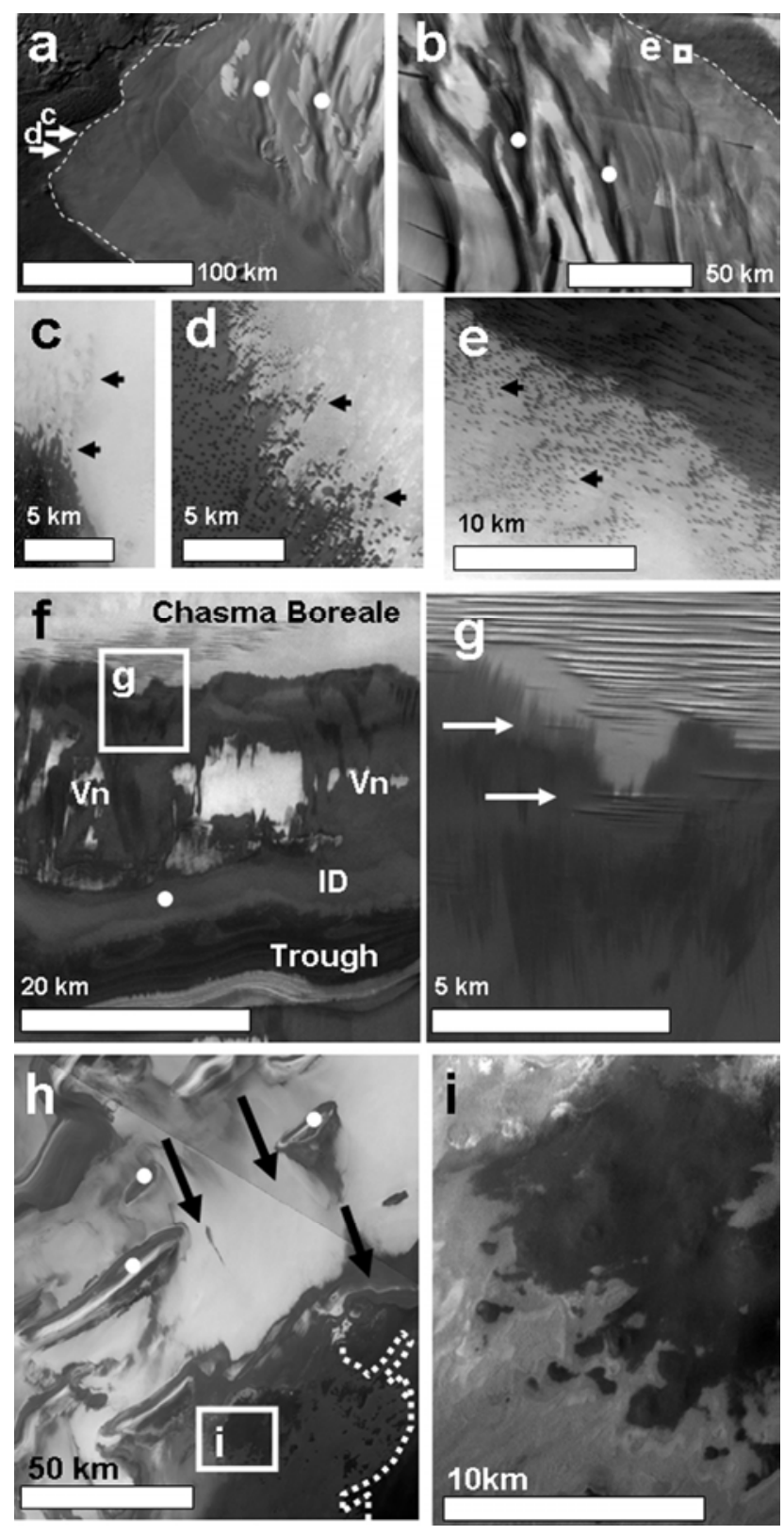

Figure 10. Dark interior deposits within polar troughs and adjacent veneers form extensive sedimentary mantles that extend onto the circum-polar erg (along dashed lines in a, part of HRSC north polar mosaic superposed on a MOLA shaded relief base and centered at $318.29^{\circ} \mathrm{W} ; 79.82^{\circ} \mathrm{N}$ ) and in $\mathbf{b}$, part of THEMIS visual-range north polar mosaic of summertime images ( $32 \mathrm{~m} /$ pixel) superposed on a MOLA shaded relief base centered at $95.86^{\circ} \mathrm{W} ; 82.10^{\circ} \mathrm{N}$. The interior deposits bury (black arrows in panel c; part of THEMIS VIS V12684010) and embay (black arrows in panels $\mathbf{d}$ and $\mathbf{e}$; respectively, parts of THEMIS VIS $\mathrm{V} 12684010$ centered at $312.56^{\circ} \mathrm{W}, 79.08^{\circ} \mathrm{N}$ and V13565005 centered at $312.51^{\circ} \mathrm{W}, 79.05^{\circ} \mathrm{N}$ ) circum-polar dunes. (f) Shown are veneers, which source from dark interior deposits within a polar trough terminate along the western margin of Chasma Boreale (part of HRSC north polar mosaic centered at $326.18^{\circ} \mathrm{W}, 83.29^{\circ} \mathrm{N}$ ), where they drape over landforms that resemble yardangs or sastrugi (white arrows in panel g). (Part of THEMIS VIS V13258004 centered at $325.64^{\circ} \mathrm{W} ; 83.50^{\circ} \mathrm{N}$.) (h) Polar troughs that contain dark interior deposits (white dots) form source regions of north polar veneers. The orientation of the north polar veneers (black arrows) suggests that sediments were transported and deposited into a mantle along the periphery of Planum Boreum (margin outlined with the dotted white line; part of HRSC north polar mosaic centered at $46.21^{\circ} \mathrm{W} ; 80.42^{\circ} \mathrm{N}$ ), which embays an older dark and cratered surface which may be part of the Vastitas Borealis interior unit, or the Rupes Tenuis unit (i) (Part of THEMIS VIS V12918003 centered at $43.26^{\circ} \mathrm{W}$; $79.71^{\circ} \mathrm{N}$ ). (figure10.jpg)

indistinguishable with present data from the sedimentary mantles we describe.

Surface ULD undulations, which are widespread in Gemina Lingula, may represent zones where there are polar troughs buried under both ID and ULD materials (Figure 12a) This interpretation is indicated by (1) the alignment and continuity of polar troughs and ULD undulations (Figure 5), (2) the existence of enclosed troughs that contain dark interior deposits along ULD undulations (Figure 5), and (3) the fact that ULD appear locally degraded where it passes into polar troughs (Figure 6). Therefore, we propose that the locations of ID represent exhumed zones in Planum Boreum where there has been degradation, retreat and net removal of ULD materials along surface undulations (Figure 6).

In fact, the emplacement of north polar veneers along the margins of outcrops of ID would have locally decreased the surface albedo leading to surface warming and potentially driving off interstitial ice and/or shallow buried ice, as well

as perhaps inhibiting water-ice accumulation. In addition, surface abrasion produced by salting particles during veneer migration would have also contributed to localized surface erosion and degradation. As a result, localized exhumation of the ID could have triggered sequences of self-propagating episodes of ULD retreat, veneer generation and polar trough exhumation.

We have identified transient plumes, presumably produced by katabatic winds, that terminate in north polar veneers (Figure 13a and 13d) and which in one case initiates at an ID layer within a polar trough (Figure 13b and 13c), indicating that the formation of north polar veneers may indeed be an ongoing process. These observations suggest that the veneers may consist of (or contain) dust-sized sedimentary particles that were deposited out of suspension, perhaps in similar manner to deposits of dust plumes on Earth (e.g., Breed and McCauley 1986; Middleton and Goudie 2001). Aeolian mobilization of the outcropping ID materials led to the deposition of sedimentary lags in the form of surface veneers. The fact that in extensive regions of Planum Boreum the water-ice signature of the ULD and residual ice cap is suppressed by north polar veneer deposits (Figure 1) indicates that the north polar veneers are younger than the residual ice cap, and thus form the youngest stratigraphic unit in Planum Boreum (Figure 12b). The latest age estimate for the residual ice (upper most layer of the ULD) appears to be $<20 \mathrm{ka}$ (Tanaka 2005). The fact that zones of ID and north polar veneer occurrence lack a water-ice signature (Figures 1 and 2) 
is consistent with a lithic composition.

The surface of the ULD and the residual ice cap commonly display striations (grooves and ridges) (Figures 4e, 11b, and 11c), and these do not appear to be of deformational origin (Tanaka 2005). These surface striations are in places aligned with streaks that form the margins of north polar veneers (Figures 4d-f), which suggests that surface erosion into striations may have resulted from abrasion by sand-sized particles migrating along the direction of north polar veneer propagation. Indeed, north polar veneers comprise the most widespread sedimentary deposits on the surface of Planum Boreum (Figure 12b), and thus surface erosional processes associated with their emplacement can account for the widespread occurrence of striations across Planum Boreum. Specific mesoscale atmospheric circulation model outputs describe (1) high easterly ( $\sim 10 \mathrm{~m} / \mathrm{s})$ winds, (2) off-cap, katabatic winds $(\sim 5 \mathrm{~m} / \mathrm{s})$, and (3) strong, summertime $\left(\mathrm{L}_{\mathrm{s}} \sim\right.$ $120)$ excursion winds (10-15 m/s) along the residual ice cap edge over Chasma Boreale and along the margin of Planum Boreum near Olympia Undae (Tyler and Barnes 2005). For typical current-day surface atmospheric pressures around 5-10 mbar (500-1000 Pa) and sand-size particles 50-200 $\mu \mathrm{m}$ in diameter of basaltic density, threshold windspeeds required to induce saltation ranges from $15-35 \mathrm{~m} / \mathrm{sec}$. (Greeley et al. 1980), which is consistent with the ULD materials along the margin of Planum Boreum having been eroded by sand into knobby ridges during the highest seasonal winds, augmented by storms, gusts, and topographic funnels (Figure 11a). In some cases, dark interior deposits within polar troughs form mantles that climb the walls of polar troughs and resemble sand ramps (Figures 7c and 7d). On Earth and Mars, the presence of sand ramps, or climbing dunes, facilitates saltation and indicates a potential sediment transport pathway out of valleys (Bourke et al. 2004). Moreover, the formation of sand ramps within polar troughs is consistent with modeled Martian aerodynamics for troughs that suggest accelerated wind velocities (up to 30\%) against downwind trough walls (Bourke et al. 2004). This may generate wind velocities sufficient to locally mobilize sand-sized sediments.

Whereas these observations suggest that the ID contain sand-sized particles, we note that striations may also be formed by snow and ice corrosion. Similar erosional processes have been suggested for the formation of sastrugi (dunes made up of snow particles) and channel-like cuts in hard-packed snow on Victoria Island, Canada (Washburn 1947). It has been shown in experimental work that dust and snow at low temperatures can abrade rocks at the micron scale (Dietrich 1977), although this has been difficult to establish under field conditions (McKenna Neuman 1993; Schlyter 1994). If dust-sized particles are indeed capable of significantly abrading the surface of Planum Boreum, and the north polar veneers consist of dust-sized particles, then their emplacement and migration could account for the existence of surface striations.

The fact that the low albedo mantles in Planum Boreum, which primarily consist of extensive systems of north polar veneers, terminate in circum-polar terrains, is suggestive of large-scale mass transfer from Planum Boreum towards its periphery. In fact, re-deposition of the ID materials appears to have been substantial along the margins of Planum Boreum where north polar veneers terminate (Figures 9 and 10) and where there are extensive mantles that bury and embay dune fields, which in this work we refer to as the veneers' terminal unit (VnT, Figures 12 and 14). If the ID consist of a mixture of sand- and dust-sized particles and the north polar veneers consist of predominantly dust-sized particles, then the VnT materials may consist of sand-sized particles carried in by saltation from outcropping ID materials (Figure 14). We propose that this trend of sustained sedimentary migration also resulted in at least the partial exhumation of numerous north polar troughs cut in the LLD (Figures 6c, 7c and 13).

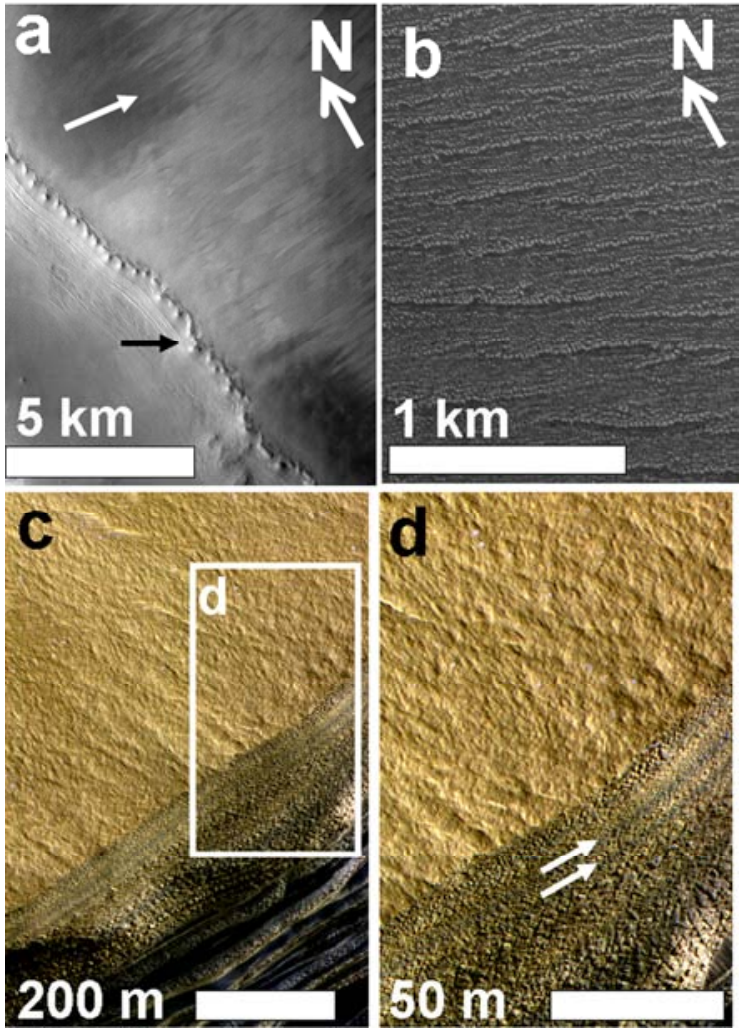

Figure 11. (a) Knobby ridge (black arrow) that forms a margin of Planum Boreum covered with veneers (white arrow) that trend perpendicular to the ridge (part of THEMIS VIS V13908037 centered at $289^{\circ} \mathrm{W}, 81.72^{\circ} \mathrm{N}$ ). The surface in veneer zones commonly displays striations in the ULD (b, part of MOC image M0001424 centered at $352.78^{\circ} \mathrm{W}, 81.10^{\circ} \mathrm{N}$ ) and the LLD (c and d, part of HiRISE PSP_001334_2645 centered at $343.65^{\circ} \mathrm{W}, 84.39^{\circ} \mathrm{N}$ ). The white arrows in panel d show a close up view of alternating low and high albedo layers in the ULD. (figure11.jpg)

Onset of north polar veneers activity. Our examination of striated ULD and LLD surfaces at MOC and HiRISE resolutions reveals the existence of scarps that display alternating low and high albedo layers. Some of the dark layers appear to have retreated to form series of benches covered in dark sedimentary deposits (Figures 11c and 11d). We interpret these observations as possible indicators of alternating episodes of ice and veneer accumulation during 
the construction of the LLD. North polar veneers overlie the residual water-ice cap, which appears to be on average less than 20,000 years old (Tanaka 2005), so the veneers are likely to be much younger than that. The residual ice cap may form and retreat on time scales of tens to hundreds of thousands of years according obliquity and perihelion cycles of Mars (e.g., Laskar et al. 2002), leading to development of the LLD and ULD stratigraphy over millions to tens of millions of years, given the hundreds to perhaps thousands of layers in these deposits.

Propagation of north polar veneers. The exhumation of intermediate deposits along polar troughs and their redeposition as widespread north polar veneers and sedimentary mantles along the periphery of Planum Boreum are indicative of highly dynamic sedimentary processes in the

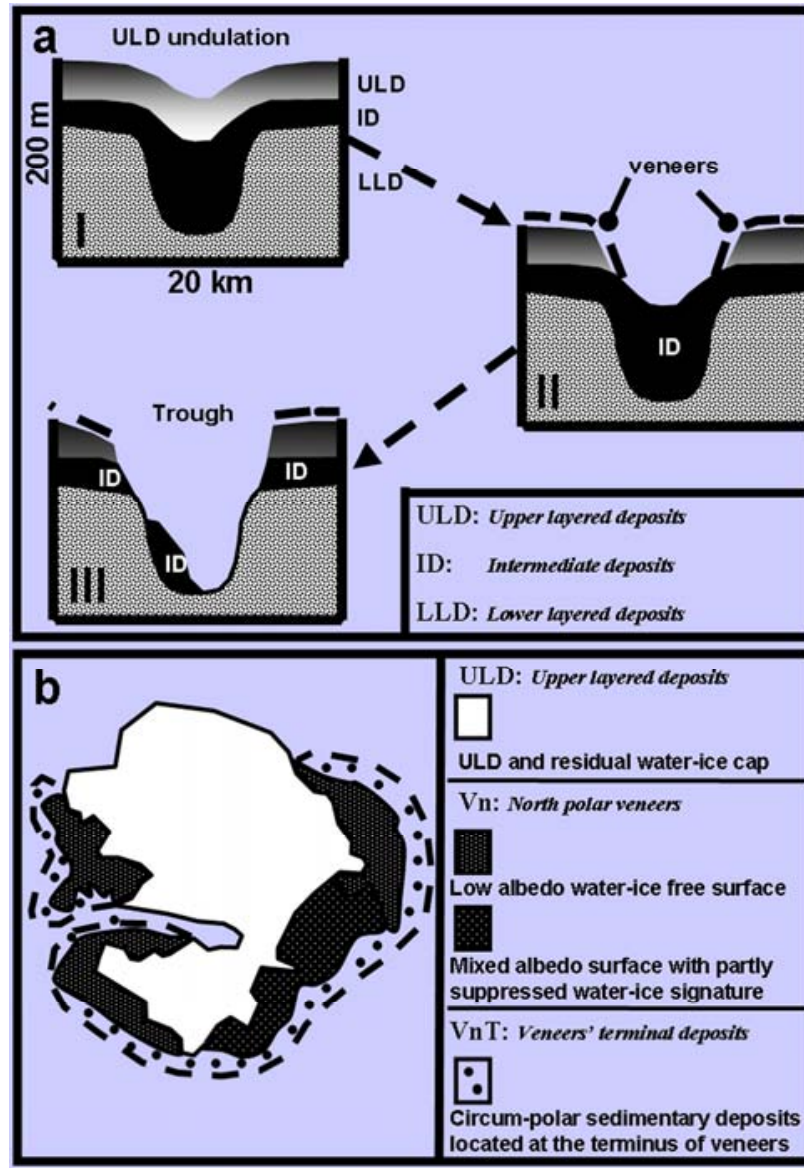

Figure 12. (a) Hypothetical model for trough exhumation and veneer formation. (I) Cross section of the polar layered materials that underlie a ULD undulation. According to this model, the undulations represent locations where polar troughs are covered by ID and ULD materials. Vertical and horizontal scales are based on cross-sections. (II) ULD retreat exhumes the underlying ID materials, which are then mobilized by katabatic winds into veneers that spread over the adjacent plateau surfaces. (III) Sustained removal of the ID materials exposes the underlying LLD that forms the floors of pre-existing troughs. (b) Map figure showing the distribution of sedimentary mantles in Planum Boreum that completely, or partly, suppress the surface water-ice signature. (figure12.jpg) recent history of the north polar plateau.

This is in apparent contradiction with the fact that most circum-polar dunes, which form the most abundant recent sedimentary features in the region, appear to be stable, and possibly even fossilized (Tanaka 2005). Rapid emplacement and high mobility of north polar veneer sedimentary particles are suggested by: (1) the fact that although superposition of polar veneers is commonly observed, they do not appear to be thick enough to completely bury the underlying plateau surface texture (Figures 2 and 3), (2) the fact that common landforms in sandy aeolian deposits such as ripples or dunes are not observed in the veneers (Figure 4f), and (3) the fact that north polar veneers overlap extensive surfaces of the residual water-ice cap (Figure 1).

In some cases, sedimentary plumes emerging from polar troughs consist of multiple parallel vortices (e.g., Figures 13c and 13d). These may indicate pathways of sedimentary migration, including those of the saltating particles that may have resulted in differential erosion of the surface and the formation of striations. We propose that the formation of striations may have led to wind funneling, thereby increasing wind speed within them and thus increasing the efficiency of saltation and erosion. This process would be analogous to the formation of terrestrial yardangs (e.g., Ward and Greeley 1984). Thus, in spite of the low density of the Martian atmosphere, north polar veneers form part of a highly dynamic sedimentary environment, which could account for the apparent relatively rapid emplacement of north polar veneers, and the apparent stability of north polar dunes. Other factors that may have contributed to the high mobility of sedimentary particles forming the north veneers include: (1) repulsive electrostatic charging (Kolesnikov and Yakovlev 2003); (2) low angle of internal friction of cohesionless particles, which could be related to a high degree of particle sphericity and/or particle levitations due to electrostatic charges (Lambe and Whitman 1969); and/or (3) sustained saltation over frozen surfaces at low wind shear velocities (McKenna 1989).

The multiple orientations of north polar veneers at local and regional scales are indicative of variable recent wind regimes (e.g., Figure 7). Changes in wind direction and the subsequent superposition of striation patterns can explain the formation of pitted textures in the polar plateau (Tanaka 2005).

\section{North polar veneers superposition relations}

Albedo variability of north polar veneers. Superposition relations indicate that the albedo of progressively older veneers is typically (but not always) brighter (e.g., Figure 4a), which may explain the discontinuity of some veneer deposits (Figure 10h). OMEGA data reveals that relatively high albedo north polar veneers (Figure $3 \mathrm{~b}$ and $3 \mathrm{~d}$ ) correspond to terrains where the surface water-ice signature is reduced (but not completely suppressed; Figure $2 \mathrm{a}$ and $2 \mathrm{~b}$ ), indicating low to modest surface water-ice abundance.

We suggest that the brightening of veneers with age could be related to (1) the number of superposed veneers, so that the 


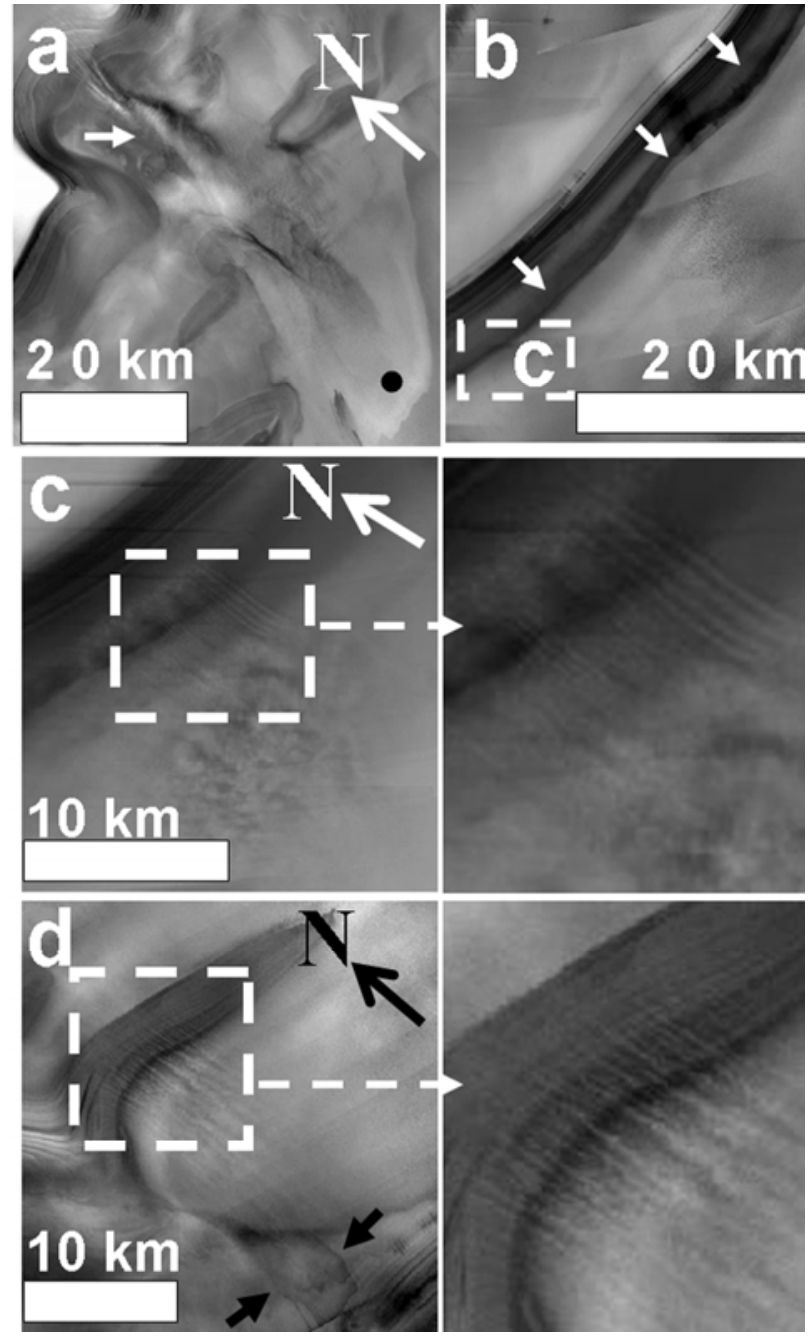

Figure 13. Examples of sedimentary plumes associated with north polar veneers. (a) Sedimentary plume (white arrow) that terminates in a north polar veneer (black dot) (part of a THEMIS summertime mosaic (32 $\mathrm{m} /$ pixel) centered at $47.55^{\circ} \mathrm{W}, 81.25^{\circ} \mathrm{N}$ ). (b) ID materials exposed as a layer along the pole-facing slope of a trough (white arrows) (part of a THEMIS summertime mosaic ( $18 \mathrm{~m} /$ pixel) centered at $67.58^{\circ} \mathrm{W}$, $\left.86.60^{\circ} \mathrm{N}\right)$.(c) Sedimentary plume emerges from the ID layer shown in panel b. Notice in close-up at right how the plume consists of multiple longitudinal vortices (part of a THEMIS summertime mosaic ( $32 \mathrm{~m} /$ pixel)). (d) Parallel plumes (left and right) emerge from pole-facing slope in a polar trough and terminate in a north polar veneer (black arrow). (Part of THEMIS summertime mosaic ( $32 \mathrm{~m} /$ pixel) centered at $50.43^{\circ} \mathrm{W}, 82.47^{\circ} \mathrm{N}$ ). See locations and contexts in Figure 1a. (figure13.jpg)

accumulation of multiple veneers locally increases the concentration of (dark) sedimentary particles overlying the icy substrate, thereby leading to darkening due to a loss of transparency and the complete suppression of water-ice signature, and/or (2) older veneer materials becoming lighter due to their chemical alteration and or coating by brighter materials such water-ice crystals (which would be consistent with the fact that relatively high albedo north polar veneers have a modest water-ice signature), $\mathrm{CO}_{2}$ frost, or salts. In this case, remobilization of older veneers may form light streaks on darker veneers. Some veneers have dark margins and brighter interiors that may indicate relative alteration within veneers as well.

Moreover, there is great variability in the relative brightness of single north polar veneers within and between various images. This may be due to the extent of the seasonal $\mathrm{CO}_{2}$ frost cap given that the images are acquired at various times in the Martian year, changes in the conditions of illumination, and/or variations in the stretches applied to individual images.

Lack of mobility of older north polar veneers. Because superposed veneers are oriented in multiple directions, it appears that changes in wind direction do not lead to the remobilization and re-orientation of the sedimentary particles that form at least the older veneers. This could be related to the fact that changes in wind direction do not lead to the re-orientation of veneer-forming particles, because they primarily consist of dust-sized particles, which is consistent with the fact that numerous north polar veneers appear to form the terminal deposits of transient plumes (Figure 13).

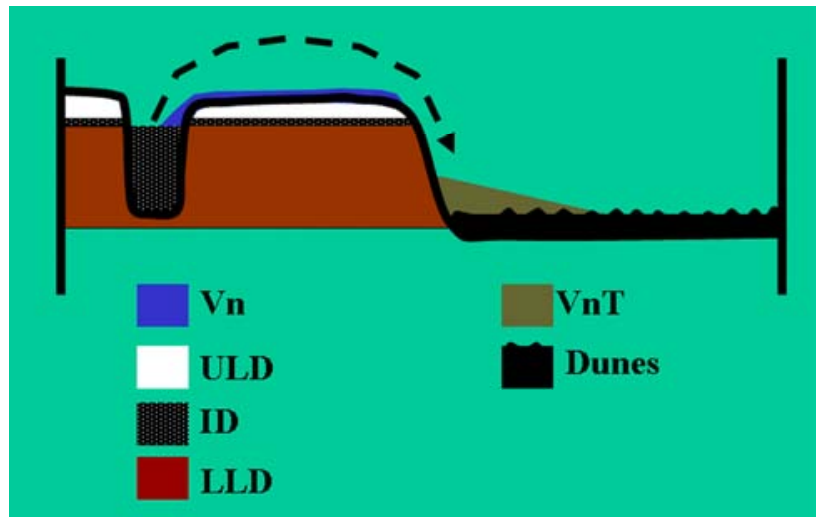

Figure 14. Illustration of north polar veneer-forming sedimentary processes in Planum Boreum. Mobilization of ID materials led to widespread mantling of the ULD by north polar veneers and to the deposition of sedimentary mantles that bury and embay circum-polar dunes. For explanation of unit symbols, see Figure 12. (figure14.jpg)

When a wind shift occurs, the sand particles may continue moving but leave behind a dust lag. Alternatively, the sand particles could break up into smaller, less mobile particles, limiting the distance of veneer migration. Hydrated salts might behave this way, since their dehydration would break down the crystalline structure, cause volume loss, and result in fine-grained dehydration products. Very soft minerals such as some hydrated salts and highly weathered silicates including glass and feldspar or olivine, might also produce dust during saltation collisions of grains, because the weathering products, such as clays or zeolites, might be released as the grain fractures.

The lack of mobility of the sedimentary particles that form the north polar veneers may also result from the formation of some type of indurated layer. The simplest process, cementation by precipitating water ice, could occur only 
where water ice is stable at the surface and can condense on the low albedo veneer surfaces; but this may indeed be what brightens the veneers. If ice is stable at the surface, then it will probably fill pore spaces and cement clastic/lithic grains very quickly. This scenario is consistent with the fact that relatively higher albedo north polar veneers appear to contain some water-ice.

If ice is not stable on low albedo materials, then something else must occur if induration is a key process. The detection of a gypsum signature in sand dunes in the north polar sea (Langevin et al. 2005) raises interesting questions about the possible roles of gypsum and other salts in polar sedimentary processes. Martian indurated sedimentary veneers may form through salt cementation if temperatures attain at least the eutectic melting point of ice-salt mixtures or the dissociation temperature of hydrated salts (Brass 1980, Marion et al. 2003, Kargel and Marion 2004). In principle, minute quantities of salts might cause sufficient induration to stabilize the veneers. Induration by salts might also be possible at cryogenic temperatures though the action of thermodynamically unfrozen water, which might carry trace amounts of solutes along grain boundaries. Transport of solutes in unfrozen water films might produce indurated crusts that may tend to stop aeolian erosion. Veneer induration by salts might also modify the local albedo and near-surface soil temperatures, such that ice may become stable in the soil, if it is not initially stable, thus further indurating the soil and making it resistant to erosion. Nevertheless, because it is likely that sand would re-mobilize the dust when it saltates, the fixation of north polar veneers must have involved some degree of cementation by salts, ice, or both.

\section{Conclusions}

This investigation permits the following conclusions to be drawn:

(1) ULD retreat has led to the exhumation of an underlying discontinuous low albedo sedimentary layer, the ID, which forms particularly thick deposits within polar troughs that underlie surface undulations.

(2) Mobilization of the ID has led to (a) the exhumation of pre-existing polar troughs, (b) extensive mantling by north polar veneers in Planum Boreum, and (c) the formation of significant sedimentary deposits around the periphery of Planum Boreum. This trend of sedimentary migration implies that Planum Boreum may be (or was recently) in a state of net degradation.

(3)Veneers may lead to lag deposits on LLD surfaces, such that potentially ice-rich LLD materials may be mantled. This might help explain why LLD seem to be nearly pure ice in MARSIS data but have low-ice abundance in OMEGA data.

(4) The lowering of surface albedo by the veneer deposits, as well as surface erosion by associated migrating sedimentary particles, appears to have prevented ice accumulation and promoted degradation in vast regions of the northern polar plateau.
(5) ID mobilization into transient plumes that terminate in north polar veneers suggest that the ID materials may contain dust-sized particles that were mobilized and re-deposited as north polar veneers. However, the existence of sedimentary ramps and widespread striations oriented along the inferred direction of north polar veneer propagation suggest that the ID materials also contain sand-sized particles.

(6) Thus, the ID appears to consist of a mixture of sand and dust, and the north polar veneers appear to consist of dust-sized particles. We suggest that the sedimentary deposits that surround Planum Boreum, and which are situated at the zones where the sedimentary mantles made up of north polar veneers terminate, may consisted of sorted sand-sized particles (Figure 14).

(7) Finally, stratigraphy (dust and snow layers) in ice cores on Earth is used to reconstruct paleoclimate. The assumption is that the dust layers are airfall deposits. This work shows that there are other significant endogenic sediment sources, and if these 'recent' episodes also happened in the past, then the observed layering may not all signify airfall events but may include some veneer deposits, which has important implications for the interpretation of PLD stratigraphy to infer paleo-climate signals (e.g., Milkovich and Head 2005, Laskar et al. 2002).

\section{Directory of supporting data}

root directory

manuscript.pdf this file

Fig. 1 figure1.jpg full-resolution image

Fig. 2 figure2.jpg full-resolution image

Fig. 3 figure3.jpg full-resolution image

Fig. 4 figure4.jpg full-resolution image

Fig. 5 figure5.jpg full-resolution image

Fig. 6 figure6.jpg full-resolution image

Fig. 7 figure7.jpg full-resolution image

Fig. 8 figure8.jpg full-resolution image

Fig. 9 figure9.jpg full-resolution image

Fig. 10 figure10.jpg full-resolution image

Fig. 11 figure11.jpg full-resolution image

Fig. 12 figure12.jpg full-resolution image

Fig. 13 figure13.jpg full-resolution image

Fig. 14 figure14.jpg full-resolution image

\section{References}

Benito, G., F. Mediavilla, M. Fernandez, A. Marquez, J. Martinez and F. Anguita (1997) "Chasma Boreale, Mars: a sapping and outflow channel with a tectono-thermal origin" I carus 129, 528-538.

Bourke, M. C., J. E. Bullard and O. S. Barnouin-J ha (2004) "Aaeolian sediment transport pathways and aerodynamics at troughs on Mars" J ournal of Geophysical Research 109, E07005. doi: 10.1029/2003]E002155

Brass, G. W. (1980) "Stability of brines on Mars" I carus 42, 20-28.

Breed, C. S. and J. F. McCauley (1986) "Use of dust storm observations on satellite images to identify areas vulnerable to severe wind erosion" Climatic Change 9, 243-258. 
Byrne, S. and B. Murray (2002) "North polar stratigraphy and the paleo-erg of Mars" J ournal of Geophysical Research 107, E6.

Cutts, J. (1973) "Nature and origin of layered deposits of the Martian polar regions" J ournal of Geophysical Research 78, 4231-4249.

Dietrich, R. V. (1977) "Impact abrasion of harder by softer materials" J ournal of Geology 85, 242-246.

Dietrich, R. V. (1977) "Wind erosion by snow" Journal of Glaciology 18, 148-149.

Edgett, K. S. and P. R. Christensen (1991) "The particle size of Martian aeolian dunes" J ournal of Geophysical Research 96, 22765-22776.

Fishbaugh, K. and J. Head (2000) "North polar region of Mars: topography of circumpolar deposits from Mars Orbiter Laser Altimeter (MOLA) data and evidence for asymmetric retreat of the polar cap" J ournal of Geophysical Research 105, 22455-22486.

Fishbaugh, K. and J. Head (2002) "Chasma Boreale, Mars: topographic characterization from Mars Orbiter Laser Altimeter data and implications for mechanisms of formation" J ournal of Geophysical Research 107, E3.

Fishbaugh, K. and J. Head (2005) "Origin and characteristics of the Mars north polar basal unit and implications for polar geologic history" I carus 174, 444-474. doi: 10.1016/j.icarus.2004.06.021

Fisher, D. (2000) "Internal layers in an 'accublation' ice cap-A test for flow" I carus 144, 289-294.

Greeley, R., R. Leach, B. R. White, J. Iversen and J. Pollack (1980) "Threshold windspeeds for sand on Mars: Wind tunnel simulations" Geophysical Research Letters 7, 121-124.

Herkenhoff, K. (2003) "Geologic map of the MTM 85080 quadrangle Chasma Boreale region of Mars." U.S. Geological Survey Geophysical Investigations Series Map I-2753.

Howard, A. D., J. A. Cutts and K. R. Blasius (1982) "Stratigraphic relationships within Martian polar cap deposits" I carus 50, 161-215.

Howard, A. D. (2000) "The role of eolian processes in forming surface features of the Martian polar layered deposits" I carus 144, 267-288.

Howard, A. D. (1978) "Origin of the stepped topography of the Martian poles" Icarus 34, 581-599.

Kargel, J. S. and G. M. Marion (2004) "Mars as a salt-, acid-, and gas-hydrate world" Lunar and Planetary Science 35, 1965.

Kolb, E. and K. Tanaka (2001) "Geologic history of the polar regions of Mars based on Mars Global Surveyor data: II. Amazonian Period" I carus 154, 22-39.

Lambe, T. W. and R. V. Whitman (1979) Soil Mechanics, Wiley, John \& Sons.

Langevin, Y., J.-P. Poulet, E. K. Kolesnikov and A. B. Yakovlev (2003) "Vertical dynamics and horizontal transfer of submicron-sized lunar-regolith microparticles levitating in the electrostatic field of the near-surface photoelectron layer" Planetary and Space Science 51, 879-885.

Langevin, Y., Poulet, J.-P. Bibring and B. Gondet (2005) "Sulfates in the north polar region of Mars detected by OMEGA/Mars Express" Science 307, 1584-1586. doi: 10.1126/science.1109091

Laskar, J., B. Levrard and J. F. Mustard (2002) “Orbital forcing of the Martian polar layered deposits" Nature 419, 375-377.

Malin, M. and K. Edgett (2001) “Mars Global Surveyor Mars Orbiter Camera: interplanetary cruise through primary mission" J ournal of Geophysical Research $106,23429-23570$.
Marion, G. M., D. C. Catling and J. S. Kargel (2003) “Modeling aqueous ferrous iron chemistry at low temperatures with application to Mars" Geochim. Cosmochim. Acta 67, 4251-4266. doi: 10.1016/S0016-7037(03)00372-7

Milkovich, S. M. and J. W. Head III (2005) "North polar cap of Mars: Polar layered deposit characterization and identification of a fundamental climate signal" J ournal of Geophysical Research 110, E01005. doi: 10.1029/2004JE002349

Middleton, N. J. and A. S. Goudie (2001) "Saharan dust: sources and trajectories" Transactions of the Institute of British Geographers 26, 165-181.

McKenna Neuman, C. (1989) "Kinetic energy transfer through impact and its role in entrainment by wind of particles from frozen surfaces" Sedimentology 36, 1007-1015.

McKenna Neuman, C. (1993) "A review of aaeolian transport processes in cold environments" Progress in Physical Geography 17, 137-155.

Pathare, A. and D. Paige (2005) "The effects of Martian orbital variations upon the sublimation and relaxation of north polar troughs and scarps" I carus 174, 419-443. doi: 10.1016/j.icarus.2004.10.030

Schlyter P. (1994) "Paleo-periglacial ventifact formation by suspended silt or snow - site studies in south Sweden" Geografiska Annaler, Series A 76, 187-201.

Rodriguez, J. A. P. and K. L. Tanaka (2007) “Complexity in the stratigraphic, erosional, and climatic record of the northern polar plateau of Mars" Lunar and Planetary Science 37, 1808.

Tanaka K. L. (2005) "Geology and insolation-driven climatic history of Amazonian north polar materials on Mars" Nature 437, 991-994. doi: 10.1038/nature04065

Thomas, P. and J. Veverka (1978) "Mars: Frost streaks in the south polar cap." Bulletin of the American Astronomical Society 10, 555.

Thomas, P., S. Squyres, K. Herkenhoff, A. Howard and B. Murray (1992) "Polar deposits of Mars" in Mars (H.H. Kieffer et al. editors) 767-795, University Of Arizona Press, Tucson.

Thomas, P. C., M. C. Malin, K. S. Edgett, M. H. Carr, W. K. Hartmann, A. P. Ingersoll, P. B. James, L. A. Soderblom, J. Veverka and R. Sullivan (2000) "North-south geological differences between the residual polar ice caps on Mars" Nature 404, 161-164.

Tyler, D. and J. R. Barnes (2005) "A mesoscale model study of summertime atmospheric circulations in the north polar region of Mars" J ournal of Geophysical Research, 110. doi: 10.1029/2004JE002356

Ward, A. W. and R. Greeley (1984) "Evolution of the yardangs at Rogers Lake, California" Bulletin of Geological Society of America 95, 829-837.

Washburn, A. L. (1947) “Reconnaisance geology of portions of Victoria Island and adjacent regions of Arctic Canada" Geological Society of America Memoir 22, 74-76.

Weijermars, R. (1986) "The polar spirals of Mars may be due to glacier surges deflected by Coriolis forces" Earth and Planetary Science Letters 76, 227-240.

Zimbelman, J. R. and S. H. Williams (1996) "Wind streaks: Geological and botanical effects on surface albedo contrast" Geomorphology 17, 167-185. 